\title{
Pelatihan Pembuatan Video Pembelajaran Bagi Guru KB/TK Alfath Bunulrejo Kota Malang
}

\author{
Arief Prasetyo $^{* 1}$, Elok Nur Hamdana ${ }^{2}$, Meyti Eka Apriyani ${ }^{3}$, M. Unggul Pamenang ${ }^{4}$, Sofyan Noor Arief $^{5}$ \\ 1,2,3,4,5 Teknologi Informasi Politeknik Negeri Malang, Alamat: Jl. Soekarno Hatta No. 9 Malang, \\ e-mail: *1arief.prasetyo@polinema.ac.id, ${ }^{2}$ elok@polinema.ac.id, ${ }^{3}$ meytieka@polinema.ac.id, \\ ${ }^{4}$ unggul@polinema.ac.id, ${ }^{5}$ sofyan@polinema.ac.id
}

\begin{abstract}
Abstrak
Kegiatan belajar mengajar di masa pandemi menuntut para guru melakukan strategi cerdas dan inovatif agar berbagai aktifitas pembelajaran dapat dilaksanakan dengan baik dan menarik utamanya bagi anak usia dini. Kegiatan pengabdian ini bertujuan untuk meningkatkan pengetahuan guru tentang pemanfaatan video sebagai media pembelajaran dan untuk meningkatkan kemampuan guru-guru KB/TK dalam membuat dan mengembangkan media pembelajaran dengan video. Pembuatan video pembelajaran ini diharapkan menjadi sarana penunjang belajar anak selama masa pandemi selain media pembelajaran lainnya. Video pembelajaran dinilai efektif untuk mendukung sistem pembelajaran yang akan diberikan kepada anak usia dini agar tujuan belajar tercapai. Kegiatan pelatihan ini diperuntukkan bagi guru KB/TK Alfath Bunulrejo Malang yang diikuti oleh 5 orang guru. Pemilihan topik video pembelajaran disesuaikan dengan kebutuhan dan materi yang akan dijadikan media pembelajaran berbasis video. Pelatihan ini akan dilakukan secara daring dan luring dengan metode ceramah, demonstrasi, dan latihan mandiri melalui studi kasus. Materi pelatihan dimulai dengan konsep produksi media, software, storyboard, shooting, editing video, dan finalisasi. Hasil yang dicapai dari kegiatan ini adalah para guru peserta pelatihan meningkat kompetensinya dalam mengembangkan media pembelajaran berbasis video sesuai dengan kompetensi yang diajarkan kepada siswa.
\end{abstract}

Kata Kunci: pelatihan, video pembelajaran, software

\section{PENDAHULUAN}

$\mathrm{P}$ andemi Covid-19 yang masih terus mewabah hingga saat ini, menuntut semua pihak, salah satunya bidang pendidikan melakukan strategi cerdas dan inovatif agar berbagai aktifitas pembelajaran dapat dilaksanakan dengan baik. Konsep belajar tiada henti dalam segala situasi, harus menjadikan semangat para guru agar kreatif dalam rangka turut mencerdaskan peserta didik sebagai generasi emas bangsa di masa mendatang [1]. Salah satu kebijakan pemerintah untuk menekan angka korban pandemi adalah dengan cara WFH (Work From Home). Bagi lembaga pendidikan, WFH ini berarti proses belajar mengajar (PBM) yang biasanya dilakukan di ruang kelas secara langsung sekarang digantikan dengan PBM menggunakan sistem online/daring. Untuk mendukung terlaksananya proses belajar mengajar dengan sistem daring, Seorang guru harus mampu berkreasi dengan menggunakan IT. Salah satunya dengan membuat video pembelajaran. Video pembelajaran adalah suatu media yang dirancang secara sistematis dengan berpedoman kepada kurikulum yang berlaku dan dalam pengembangannya mengaplikasikan prinsip-prinsip pembelajaran sehingga program tersebut memungkinkan peserta didik mencermati materi pelajaran secara lebih mudah dan menarik. Untuk mencapai tujuan pembelajaran pada masa Pandemi Covid -19 ini, guru harus mampu membuat video pembelajaran yang berisi materi yang akan dipahami peserta didik dirumah, sehingga pembelajaran tetap bisa terlaksana tanpa harus bertemu secara langsung [2].

Berbagai macam media pembelajaran diupayakan agar dapat memberikan pemahaman siswa terhadap materi yang diberikan oleh guru sehingga dapat meningkatkan ketertarikan siswa dalam pembelajaran. Kriteria yang paling utama dalam pemilihan media adalah bahwa media harus disesuaikan dengan tujuan pembelajaran atau kompetensi yang ingin dicapai. Hasil penelitian menunjukkan bahwa kegiatan belajar mengajar akan lebih efektif dan mudah bila dibantu dengan sarana visual, dimana $11 \%$ dari yang dipelajari terjadi lewat indera pendengaran dan $83 \%$ lewat 
indera penglihatan. Bentuk-bentuk stimulus bisa dipergunakan sebagai media diantaranya adalah hubungan atau interaksi manusia, realita, gambar bergerak atau tidak, tulisan dan suara yang direkam [3].

Berdasarkan permasalahan di atas, penulis mengadakan penelitian yang bertujuan untuk meningkatkan kemampuan anak mengenal huruf diantaranya: 1) menyebutkan bunyi huruf dengan benar, 2) menyebutkan huruf awal nama bendabenda yang ada disekitarnya, 3) menyebutkan huruf akhir nama benda yang ada disekitarnya, 4) menggabungkan huruf menjadi suku kata, 5) menggabungkan suku kata menjadi kata dengan menggunakan media yang sesuai dengan tahapan tumbuh dan berkembang anak [4].

KB/TK Alfath Bunulrejo merupakan PAUD yang didirikan atas partisipasi dan dukungan masyarakat. Berdasarkan kenyataan di lapangan yang ditemui selama masa pandemi ini, anak belum sepenuhnya mampu mengenal huruf, kalaupun ada itupun hanya sebagian kecil saja. Apabila dikaitkan dengan kurikulum yang ada, kemampuan anak masih sangat rendah dan anak belum berkembang sesuai indikator yang ada pada kurikulum tersebut.

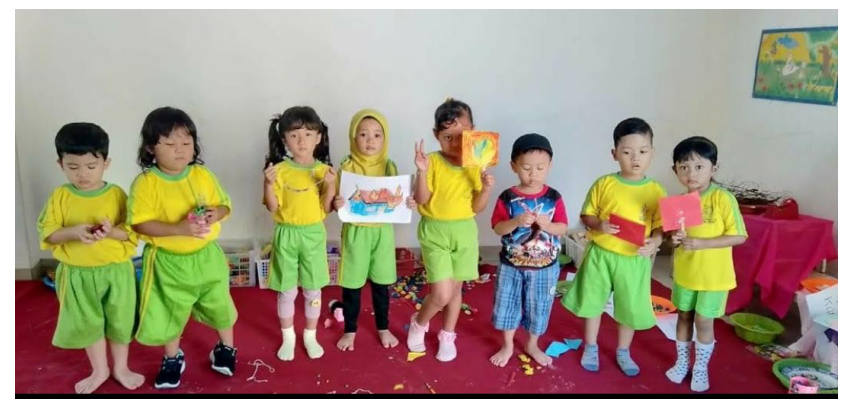

Gambar 1 Kegiatan pembelajaran di dalam kelas

Dari permasalahan tersebut, maka dalam kegiatan pengabdian pada masyarakat ini akan melakukan pelatihan media pembelajaran berbasis video dengan menggunakan software seperti OBS Studio. Diharapkan pelatihan ini dapat membantu para guru dalam proses belajar mengajar seperti pengenalan huruf, hewan, buah dan sebagainya secara interaktif dan menarik sehingga dapat meningkatan minat belajar anak-anak usia dini.

\section{METODE}

Metode yang digunakan dalam pelatihan pembuatan video pembelajaran untuk Guru KB/TK Alfath Bunulrejo akan diberikan dalam bentuk daring atau bentuk praktikum secara langsung dengan mempertimbangkan faktor protokol kesehatan Covid19. Tempat pengabdian masyarakat ini berada di KB/TK Alfath Bunulrejo yang beralamat di Gang 3 Jl. Hamid Rusdi No.179-180, Bunulrejo Kecamatan Blimbing Kota Malang Jawa Timur Kode Pos 65126. PKM berlangung selama empat jam dan waktu pelaksanaan akan diselenggarakan tanggal 23 Juni 2021 (tentatif).

Mekanisme Pelaksanaan Kegiatan pengabdian ini terdiri dari 3 (tiga) tindakan yaitu: persiapan/ perencanaan, pelaksanaan, dan evaluasi.

\subsection{Perencanaan}

Kegiatan perencanaan sebagai berikut :

- Melakukan Koordinasi dengan pihak mitra yaitu KB/TK Alfath Bunulrejo untuk mendiskusikan waktu, tempat serta materi yang akan di berikan.

- Pembuatan modul ajar untuk diberikan kepada Guru KB/TK Alfath Bunulrejo. Modul ajar yang akan diberikan dengan tema Pengenalan Huruf.

\subsection{Pelaksanaan}

Kegiatan pelaksanaan sebagai berikut :

- Pelatihan pembuatan media pembelajaran berbasis video dengan menggunakan software.

- Demonstrasi penggunaan software sebagai media pembelajaran.

\subsection{Evaluasi}

Kegiatan evaluasi dilakukan secara langsung oleh pelaksana. Evaluasi berupa hasil kerja peserta (guru mitra) terhadap pemanfaatan software dalam pembuatan video. Proses evaluasi dilaksanakan untuk mengetahui kekurangan dan kendala dalam pelaksanaan kegiatan.

\section{HASIL DAN PEMBAHASAN}

Pelatihan pembuatan video pembelajaran dilaksanakan pada tanggal 09 Juli 2021. Pelatihan tersebut bertempat di KB/TK Alfath Bunulrejo Kota Malang diikuti oleh 5 peserta yang meliputi guru dan staf. Pelaksanaan pelatihan menggunakan perangkat lunak OBS, yaitu perangkat lunak untuk membuat video yang tersedia pada PC atau laptop dan gawai pintar (smartphone). Peserta melakukan beberapa aktivitas dengan perangkat lunak tersebut seperti melakukan instalasi dan membuat proyek. Selama membuat proyek, peserta mampu mulai melakukan 
instalasi, membuat proyek video dasar dengan memberikan judul pada video, menyisipkan gambar maupun video lain. Peserta pun mampu untuk menyisipkan suara rekaman yang direkam pada perangkat lain dan menambahkan suara latar (backsound) pada video [5]. Selama pelatihan, peserta antusias dengan materi yang diberikan. Pada akhir pelatihan, peserta mulai membuat proyek materi pembelajaran masing-masing sesuai dengan yang ingin disampaikan kepada para siswa.

Sebelum dilakukan pelatihan, langkah awal adalah membuat modul pelatihan yang mana modul ini akan digunakan sebagai tutorial yang akan digunakan oleh peserta pelatihan.

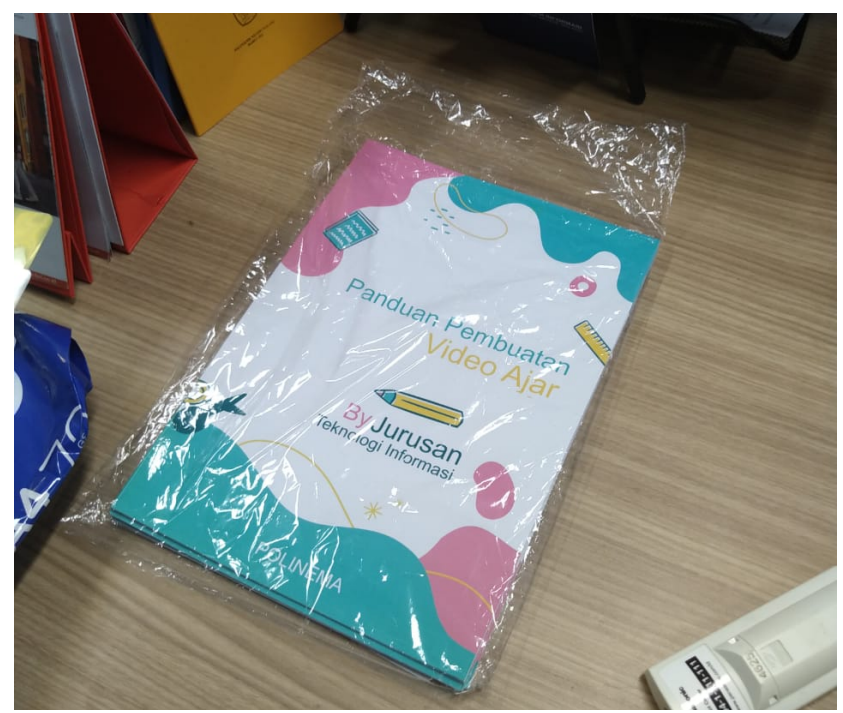

Gambar 2 Modul pelatihan

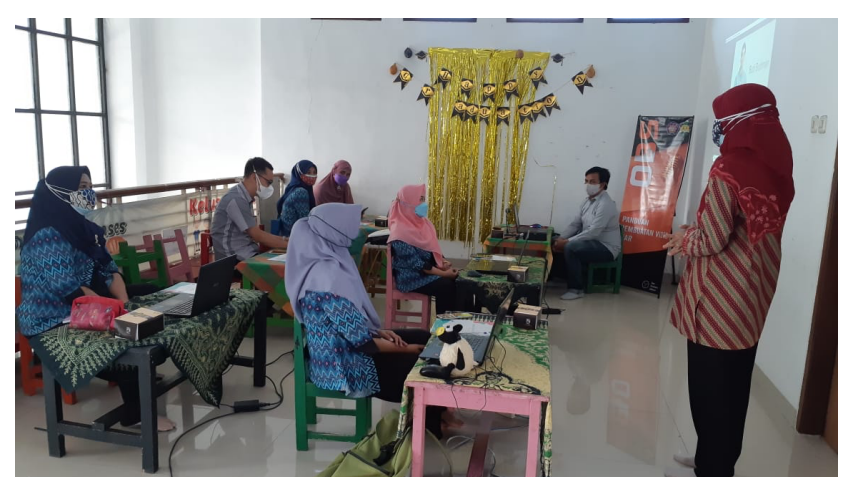

Gambar 3 Pembukaan pelatihan

Pemberian materi dilakukan secara tatap muka dengan tetap menerapkan protokol kesehatan diantaranya membatasi jumlah peserta, jarak tempat duduk dan memakai masker.

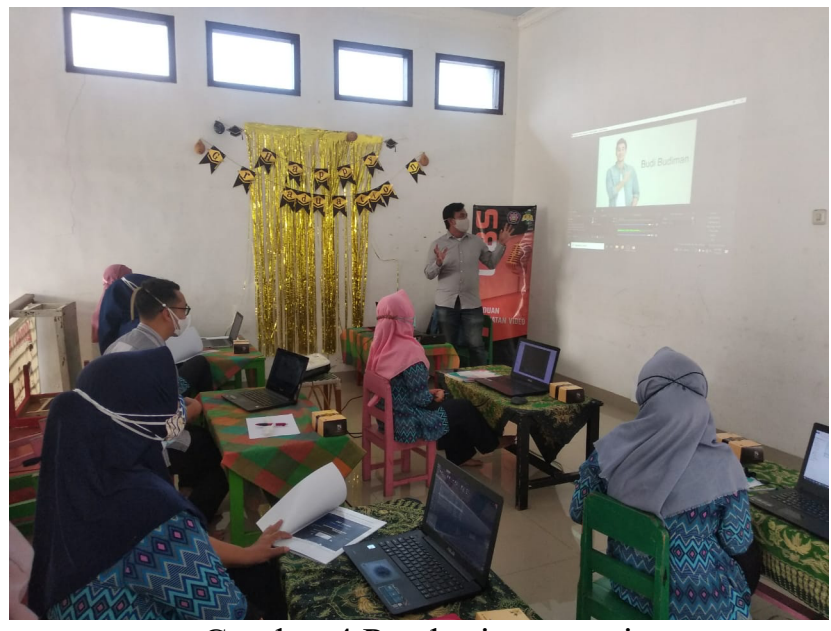

Gambar 4 Pemberian materi

Setelah penyampaian materi/teori, dilanjutkan dengan kegiatan praktek dan diskusi. Diskusi yang terjadi sangat menarik, dimana para guru menyampaikan berbagai kondisi siswa TK dan $\mathrm{KB}$ yang memerlukan hal-hal yang menarik minat dalam sebuah video yang akan dibuat. Kendala yang dihadapi selama proses pelatihan adalah masih adanya keterbatasan guru dalam mengoperasikan laptop.

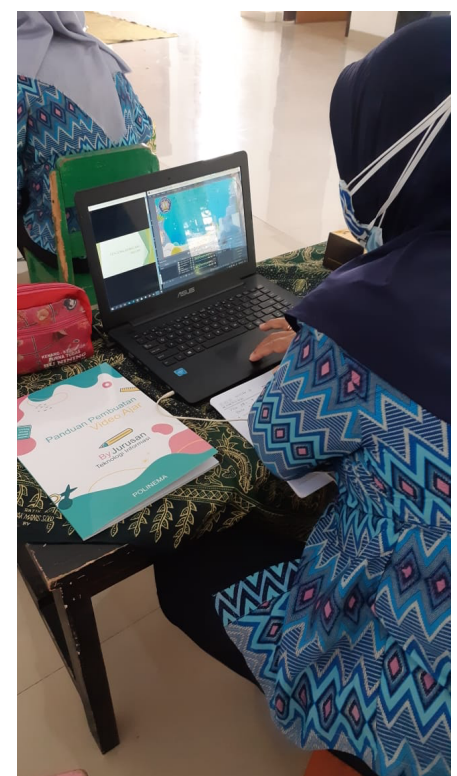

Gambar 5 Praktik pembuatan video 


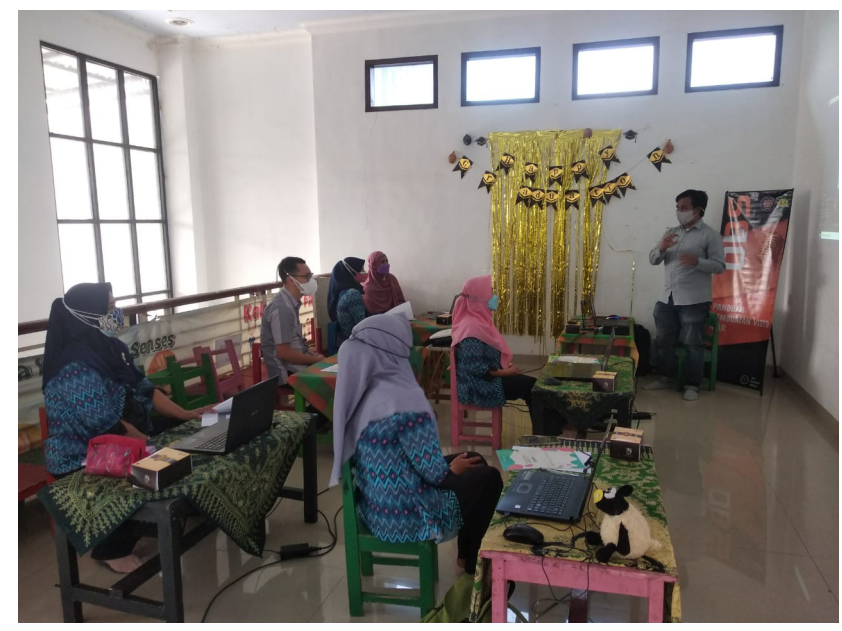

Gambar 6 Diskusi

Setelah kegiatan pelatihan berakhir, dilakukan foto bersama dosen dan guru-guru peserta pelatihan sebagai dokumentasi kegiatan.

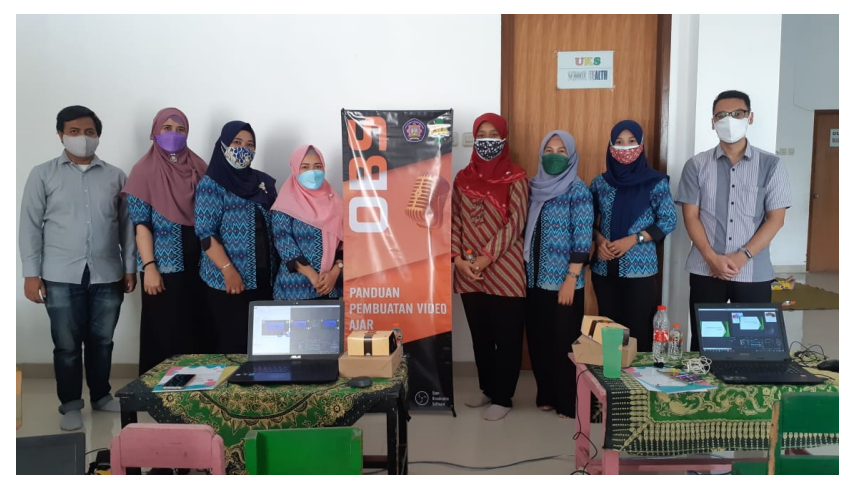

Gambar 7 Dokumentasi kegiatan

\section{KESIMPULAN}

Kegiatan pengabdian pada masyarakat dengan tema pembuatan video pembelajaran bagi guru TK/KB Alfath Bunulrejo Kota Malang telah dilaksanakan oleh tim pengabdian masyarakat interaksi Mahasiswa dan Dosen Politeknik Negeri Malang. Sebagai implementasi digunakan aplikasi OBS Studio berbasis PC atau Laptop yang dimanfaatkan sebagai alternatif aplikasi pengedit video pembelajaran untuk membuat video pembelajaran yang berisi materi pelajaran dan sarana interaksi antara guru dan siswa. Dengan menggunakan aplikasi ini, guru-guru KB/TK Alfath Bunulrejo Kota Malang menjadi lebih mudah dalam mentransfer ilmu khususnya ketika pembelajaran daring selama masa pandemi COVID-19.

\section{SARAN}

Setelah dilakukan pelatihan diharapkan guruguru dapat melanjutkan secara mandiri untuk memperkaya isi dan keberagaman materi sesuai dengan jenjang dan tujuan pembelajarannya masingmasing baik di KB maupun TK.

Selain itu, dari hasil diskusi dengan guruguru KB/TK Alfath Bunulrejo dapat diperoleh informasi bahwa $\mathrm{KB} / \mathrm{TK}$ tersebut belum mempunyai website pribadi untuk sekolah, sehingga diharapkan kedepannya bisa membantu membuatkan sistem informasi berbasis web untuk sekolah.

\section{UCAPAN TERIMA KASIH}

Penulis mengucapkan terima kasih kepada Politeknik Negeri Malang yang telah memberikan dukungan moral dan pendanaan terhadap program pengabdian masyarakat ini.

\section{DAFTAR PUSTAKA}

[1] Nurdin, N., \& Anhusadar, L., 2020, Efektivitas Pembelajaran Online Pendidik PAUD di Tengah Pandemi Covid 19, Jurnal Obsesi: Jurnal Pendidikan Anak Usia Dini, 5(1), 686. https://doi.org/10.31004/obsesi.v5i.

[2] Wakhidah, E. W., \& Umah, F. M., 2020, Penerapan Video Pembelajaran Daring Anak Usia Dini Pada Masa Pandemi Covid-19, 140160.

[3] Wulandari, H., \& Purwanta, E., 2020, Pencapaian Perkembangan Anak Usia Dini di Taman Kanak-kanak selama Pembelajaran Daring di Masa Pandemi Covid-19., Jurnal Obsesi: Jurnal Pendidikan Anak Usia Dini, 5(1), 452. https://doi.org/10.31004/obsesi .v5i1.626.

[4] Saripudin, A., \& Faujiah, I. Y., 2018, Strategi Edutainment dalam Pembelajaran di PAUD (Studi Kasus Pada TK di Kota Cirebon), AWLADY Jurnal Pendidikan Anak, 4(1), 129. https://doi.org/10.24235/awlad y.v4i1.2637. 